\title{
Balancing the life cycle impacts of notebook computers: Taiwan's experience
}

\author{
Li-Teh Lu ${ }^{a}$, Iddo K. Wernick ${ }^{\text {b,* }}$, Teng-Yuan Hsiao ${ }^{c}$, \\ Yue-Hwa Yu ${ }^{\text {a }}$, Ya-Mei Yang ${ }^{\text {a }}$, Hwong-Wen Ma ${ }^{a}$ \\ a Graduate Institute of Environmental Engineering, National Taiwan University, 71, \\ Chou-Shan Road, 10660 Taipei, Taiwan \\ b EKM International, 269 Boulevard, Passaic, NJ 07055, USA \\ ${ }^{c}$ Department of Tourism Industry, Jin-Wen Institute of Technology, 99, Ann-Chon Road, \\ 231, Taipei County, Taiwan
}

Received 20 September 2005; accepted 1 December 2005

Available online 7 February 2006

\begin{abstract}
We analyze the economic incentive structure as well as the environmental implications of the current national policy for recycling notebook computers (NB's) in the nation of Taiwan. Using cost-benefit analysis and formal life cycle assessment (LCA) we critique the current program and recommend future improvements. The current policy requires manufacturers to pay a recycling fee for each unit sold domestically. These payments are channeled to third party recycling agents as well as consumers that return used NB's. While sound in principle, the arrangement falls short of providing incentives for sustaining the domestic recycling infrastructure, scarcely covering operating costs and leaving little capital to develop new recycling technologies. The current program also fails to induce widespread consumer participation by relying on an economic incentive that compares poorly with the value obtainable from resale on the second-hand market. An environmental assessment of various end-of-life disposal options for NBs reveals that recycling for some components actually leads to greater negative environment impacts than the alternatives. Economic efficiency of the program was analyzed by integrating the life cycle assessment and the cost-benefit analysis. Our assessment suggests that a revised policy should hold manufacturers directly responsible for the development of recycling technologies and encourage changes in the design phase of the commercial life cycle rather than stressing recovery and recycling. Because of Taiwan's premier position in global NB
\end{abstract}

\footnotetext{
* Corresponding author. Tel.: +1 973246 4621; fax: +1 2125238189 .

E-mail address: iw4@ columbia.edu (I.K. Wernick).
} 
manufacturing, and in light of numerous international initiatives mandating electronic waste recycling, national policies should coordinate domestic manufacturing with foreign programs to reduce the environmental impact from NBs across the life cycle in nations around the globe.

(C) 2006 Elsevier B.V. All rights reserved.

Keywords: Notebook computers; Recycling; Recovery; Life cycle assessment (LCA); Cost-benefit analysis

\section{Introduction}

The global problem of growing solid waste streams impacts Taiwan in particular due to the high population density $\left(624.6\right.$ persons $/ \mathrm{km}^{2}$ in 2003$)$ of this island nation. From 1980 to 2000, when Taiwan experienced a period of sustained industrial development and a dramatic rise in living standards, per capita municipal waste generation rose more than $80 \%$ (from $0.63 \mathrm{~kg}$ in 1981 to $1.15 \mathrm{~kg}$ in 2000 (TEPA, 2001)). In response, the government of Taiwan initiated development of comprehensive policies for material recycling and reuse for packaging and consumer products.

In 1997, the Legislative Yuan (i.e., Taiwan's parliament) ratified the Waste Disposal Act Amendments (AWDA) and began to promote the "Four in One Resource Recycling Initiative". The law covers a broad range of consumer products including bottles, motor vehicles, used tires, white goods, personal computers and accessories. The objective of the law is to place more responsibility on manufacturers that contribute to the eventual generation of waste by the consuming public. Under the AWDA, manufacturers are required to pay recycling fees for each unit produced and sold domestically. For the case of NB's, the vast majority (over 98\%) of units are produced for export and are therefore exempt from the fee.

While this program is considered to be among the most aggressive in the Asian Pacific Region, it parallels several other international initiatives. For example, in 2003 the European Union (EU) issued a unified standard for Waste Electrical and Electronic Equipment (WEEE), mandating laws for the disposition of post consumer electronic products including white goods, small appliances, computers and related accessories such as monitors (The European Parliament And The Council Of The European Union, 2003). In 1998 Japan also passed collection and recycling regulations for household appliances and expanded the law to mandate voluntary participation by manufacturers in collecting discarded items covered by the regulation (Japan Ministry of Economy, Trade and Industry, 1998). While similar to these other initiatives, the Taiwan law stands out in making manufacturer participation mandatory in the collection and recycling of electronic products in the waste stream. Despite initiatives from several US states and localities, to date, the United States has not issued national standards pertaining to the collection and recycling of household appliances and electronic waste (Chiang, 2000).

\section{The current status of $\mathrm{NB}$ recycling in Taiwan}

The Taiwan Environmental Protection Agency (TEPA) began its mandatory program for recovery and recycling of used electronic products and other consumer products beginning 


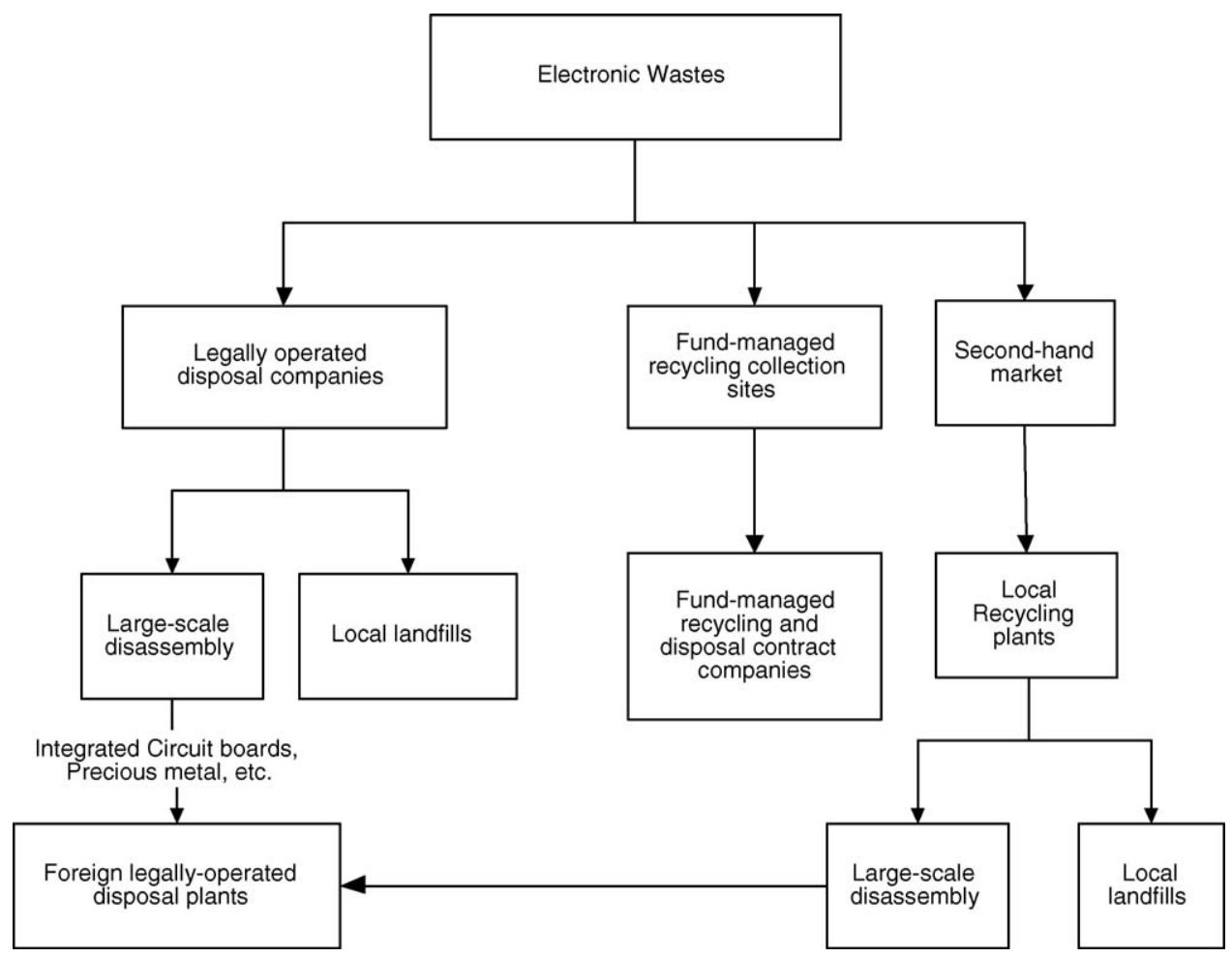

Fig. 1. Flow diagram for recycling and disposal of electronic wastes in Taiwan.

in June 1998. Seven items were included in the mandatory collection list: computer mainframes, notebook computers, monitors, printers, computer cases, hard disk and power supplies.

Under the regulation, manufacturers are required to pay a fixed fee per unit sold to a centralized fund administered by the TEPA's Fund Management Committee (FMC). The purpose of the fund is to (a) provide support for resource recovery infrastructure, such as the establishment of recycling collection sites, and to (b) subsidize payments to consumers that return used equipment to recycling collection sites.

Typically, local recycling plants disassemble electronic wastes to retrieve valuable materials such as large pieces of plastic and metal that are then sold on the second-hand market. Valuable components, such as integrated circuit (IC) boards and materials containing precious metals, are removed and sent offshore for further processing and the remaining material is transferred to local landfills (USGS, 2001). Fig. 1 shows the flow of material under the current recycling program in Taiwan for electronic wastes.

By 2004, more than 700 recovery sites were established across the country to collect used electronic equipment and ship it to approved plants for disassembly and resource recovery.

Seven computer recycling agents receive used equipment from these collection sites and operate approved plants in Taiwan. These agents, all small enterprises with less than 50 employees, lack the capital to maintain any independent research \& development capacity, 
Table 1

Number of recycled units and fees for used NBs in Taiwan 1998-2003

\begin{tabular}{|c|c|c|c|c|}
\hline Year & $\begin{array}{c}\text { Domestic } \\
\text { sales (units) }\end{array}$ & $\begin{array}{c}\text { Total \# } \\
\text { recycled } \\
\text { (units) }\end{array}$ & $\begin{array}{c}\text { Percentage } \\
\text { recycled (\%) }\end{array}$ & $\begin{array}{c}\text { Recycling fees collected } \\
\text { from manufacturers } \\
\text { (1000 NTDs) }\end{array}$ \\
\hline 1998 & 11,500 & 458 & 3.98 & $2,300.0$ \\
\hline 1999 & 25,350 & 1,090 & 4.30 & $3,954.6$ \\
\hline 2000 & 40,530 & 1,828 & 4.51 & $4,539.4$ \\
\hline 2001 & 55,050 & 1,662 & 3.02 & $2,862.6$ \\
\hline 2002 & 373,195 & 2,866 & 0.77 & $19,406.1$ \\
\hline 2003 & 455,278 & 2,507 & 0.55 & $23,674.5$ \\
\hline Total & 960,903 & 10,411 & 1.08 & $56,737.2$ \\
\hline
\end{tabular}

Source: Taiwan's EPA website: http://www.epa.gov.tw.

Table 2

Responses to survey on the sufficiency of 100 NTDs as the fee paid to consumers ${ }^{\text {a }}$

\begin{tabular}{lcc}
\hline Response & \# of Responses & Ratio \% \\
\hline Yes & 342 & 15.3 \\
No & 971 & 43.4 \\
The problem is not rewards & 805 & 36.0 \\
Other & 117 & 5.2 \\
Total & 2235 & 100 \\
\hline
\end{tabular}

a The total survey sample size was 2235 respondents, at a $95 \%$ confidence level. The margin of error was $2.2 \%$.

severely limiting national development of new recycling technology (Chang, 1998). The relatively small number of units entering the program portends a weak recycling market and further serves to discourage the investment of private capital in commercial recycling facilities. In 2002, the per unit subsidies received by these commercial recycling agents, 309 New Taiwan Dollars (NTDs), ${ }^{1}$ failed to even cover the estimated 460 NTD cost of recycling for each used NB. Table 1 shows the number of NB units sold and recycled annually as well as the sum of the fees collected from manufacturers.

While the number of units sold domestically increased nearly 40-fold from 1998 to 2003 , the amount collected from manufacturers grew only 10-fold due to the fact that the per unit fee paid by manufacturers fell nearly $75 \%$ over this period. Over the same period the subsidies paid to recyclers rose only $9 \%$. Contrary to the initial intent of the law, funding for the domestic recycling infrastructure became more of a burden for the government and small recycling enterprises and less of a responsibility for product manufacturers.

One reason for the low level of consumer participation is the size of the fee paid to consumers for bringing in used equipment, about 100 NTDs during 1998-2000, or the rough equivalent of US\$3. According to an independent survey authorized by the TEPA, the size of the fee plays an important role in determining whether consumers are willing to return used electronic equipment to recycling centers (Table 2). Only $15.3 \%$ of 2235 people surveyed considered 100-200 NTDs as offering sufficient incentive to bring in a used NB to a collection center. The same survey found that the sum needed to encourage

133 NTDs $\approx$ US\$ 1 . 
Table 3

Life cycle cost analysis of NB

\begin{tabular}{lcl}
\hline Item & Price/cost (NTDs) & Note \\
\hline Production cost & 28772 & Based on data provided by Acer Computer Corp. \\
Selling price & 72412 & Chiang (2000) \\
Asking price on second-hand market & 4467 & Chang (1998), Chiang (2000) \\
Selling price for second-hand NB & 8771 & Chiang (2000) \\
Unit recycling cost & 460 & Chang (1998) \\
EPA collection subsidy 1998-2001 & 100 & \\
\hline
\end{tabular}

significant consumer participation fell between 1000 and 1200 NTDs, far exceeding the amount justified by the revenue collected from manufacturers.

NBs occupy little space and are easy to store at home. Nearly three times as many of those surveyed said they would prefer to keep their used NB at home rather than returning their used NBs to recycling sites. Over $40 \%$ considered the option of selling a used NB on the second-hand market or giving it away as the preferred option. The economic incentive for selling a used NB on the second-hand market far exceeds the amount received for returning the unit to the government sponsored collection and recycling program. The average buying price offered for a second-hand NB currently in Taiwan, about 4500 NTDs, compares quite favorably with the 100 NTDs offered to consumers.

The fact is that most used electronics never enter the recycling system. A survey of consumer attitudes towards electronic waste disposal in the United States found a similar lack of enthusiasm among American consumers for returning used equipment. A full $75 \%$ of consumers preferring to store used computers at home and only $15 \%$ expressing any interest in reuse or recycling (Matthews et al., 1999). In a separate study in Taiwan researchers found that the bulk (79\%) of used electronic products collected never enter the collection and recycling system (Chang, 1998).

The high resale value of as much as 8771 NTDs for refurbished NB's offers a further reason for low consumer participation in the program (Table 3 ).

\section{Environmental impacts from recycling}

Having evaluated the economic incentive embedded in the domestic recycling program in Taiwan, we now turn to the environmental impact of recycling activities. The typical NB computer consists of relatively large pieces of recoverable materials as well as smaller more specialized components. The main components comprising a NB include the hard disk (HD), floppy disk drive (FDD), control unit, battery, liquid crystal display (LCD), outer housing and keyboard. Table 4 shows a breakdown of the materials comprising the NB components by weight.

Because they contain large amounts of easily recovered materials and few toxic elements, approximately $90 \%$ of the hard disk and floppy disk are recyclable. The recycling ratios for power supplies, integrated circuit and monitors were 80, 65 and 50\%, respectively (Lee et al., 2000). Because of their more intricate construction and toxic content, the LCD and the control unit which comprise 7 and $25 \%$ of the total weight, respectively, are more problematic. 
Table 4

Composition of NB by weight

\begin{tabular}{|c|c|c|}
\hline Component & Material & Average weight (g) \\
\hline \multicolumn{3}{|l|}{$\mathrm{HD}$} \\
\hline Cover & Plastic (PS) & 34.58 \\
\hline Body & Aluminum, plastic (PS) & 125.59 \\
\hline Electric function unit & Misc. & 27.44 \\
\hline \multicolumn{3}{|l|}{ FDD } \\
\hline \multirow[t]{2}{*}{ Body } & Steel, Aluminum & 143.77 \\
\hline & Plastic (PS) & 27.90 \\
\hline Electric function unit & Misc. & 25.90 \\
\hline Other component & & 28.99 \\
\hline \multicolumn{3}{|l|}{ Control unit } \\
\hline ICs & See Appendix B & 239.98 \\
\hline Printed board & See Appendix B & 360.95 \\
\hline \multicolumn{3}{|l|}{ Battery } \\
\hline Rechargeable battery & Lithium & 196.66 \\
\hline Internal battery & & 7.51 \\
\hline Base & Plastic (ABS) & 7.83 \\
\hline \multicolumn{3}{|l|}{$\mathrm{LCD}^{\mathrm{a}}$} \\
\hline \multirow[t]{8}{*}{ Glass board } & Glass & 102.00 \\
\hline & PET (film) & 17.80 \\
\hline & PS (spacer) & 0.10 \\
\hline & Cyclohexane & 0.30 \\
\hline & Gel (epoxy resin 1) & 8.90 \\
\hline & Toluene A & 0.87 \\
\hline & Copper & 12.00 \\
\hline & Cadmium & 12.00 \\
\hline \multicolumn{3}{|l|}{ Housing } \\
\hline \multirow[t]{2}{*}{ Body } & Steel, Aluminum & 109.90 \\
\hline & Plastic (ABS) & 719.91 \\
\hline \multicolumn{3}{|l|}{ Keyboard } \\
\hline Keys & Plastic (ABS) & 92.65 \\
\hline Base & Steel sheet & 32.32 \\
\hline Key foil & Plastic (PET) & 15.06 \\
\hline Electric function unit & Misc. & 5.80 \\
\hline
\end{tabular}

Source: Tung and Wu (1999), Atlantic Consulting and IPU (1998).

a The use of mercury backlight for LCD displays is not accounted for in the LCA calculation as advances in the late 1990 and early 2000s have allowed many manufacturers to produce generate backlighting using a variety of substitutes including Xenon gas, LEDs, and carbon nanotubes.

The LCD, contains the chemicals toluene A, cyclohexane, pyrimidine and biphenyl, as well as heavy metals and thus is considered a prime source of contaminants after disposal. Concerns over the release of heavy metals from used NBs in the solid waste stream are determined by means of digestion tests that measure the likelihood of metal leaching from products when residing in municipal solid waste landfills. While other components of used NBs are merged with the desktop computer recycling process, the TEPA currently recom- 
Table 5

Results of leaching tests for heavy metal for LCD

\begin{tabular}{lll}
\hline Heavy metal & By strong acid $(\mu \mathrm{g} / \mathrm{g})$ & TCLP $(\mu \mathrm{g} / \mathrm{g})$ \\
\hline $\mathrm{Cr}$ & $49.28-134.4$ & ND \\
$\mathrm{Ni}$ & $\mathrm{ND}-16.01$ & $5.17-73.6$ \\
$\mathrm{Cu}$ & $0.17-100.18$ & $7.75-656.9$ \\
$\mathrm{Zn}$ & $\mathrm{ND}-6677.3$ & ND-10.5 \\
$\mathrm{As}$ & $0.33-60.1$ & ND-0.68 \\
$\mathrm{Cd}$ & $\mathrm{ND}-3.96$ & $0.29-602$ \\
$\mathrm{Hg}$ & $\mathrm{ND}-14.12$ & ND-7.24 \\
$\mathrm{Pb}$ & $14.1-0.273$ & $2.61-13.4$ \\
\hline
\end{tabular}

Source: Tung and Wu (1999). ND, non-detectable.

mends temporarily storage of the LCD. Table 5 shows the results of heavy metal leaching tests for the LCD component.

The control unit consumes the most energy $(51.5 \mathrm{MJ})$ for manufacture and requires significant chemical inputs (see Appendix B) and thus constitutes the most problematic NB component in terms of emission and resource use. The control unit also contains hazardous heavy metals such as lead, cadmium and chromium that remain without effective treatment options in Taiwan. Environmental impact analysis comparing end of life options for discarded NB components shows that processing the control unit represents the dominant contribution to environmental impact from recycling, accounting for over $80 \%$ of the total impact as seen in the pie chart below (Fig. 2).

Our analysis combines the use of SIMAPRO 5.0, a software package for life cycle analysis, and Eco-indicator 99, a scheme for attributing activities over the commercial life cycle to impacts on human health and ecosystem quality. The complete method for impact assessment in SIMAPRO 5.0 involves characterization, damage assessment, normalization and weighting. The last three steps are optional as the data are frequently unavailable. Damage assessment in Simapro 5.0 makes use of 'endpoint methods', such as those provided by Eco-indicator 99 method.
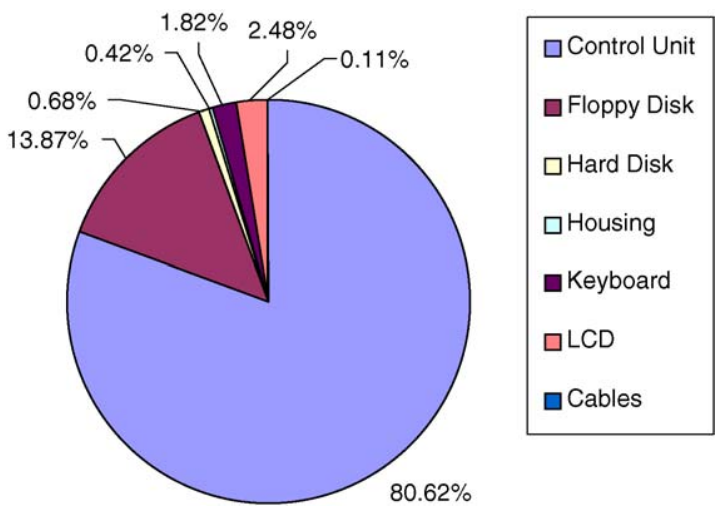

Fig. 2. Contribution to environmental impact from recycling used NB components. 
SIMAPRO (Product Ecology Consultants, 2001) was used to estimate the environmental impact for a series of disposal scenarios. Data on the weight of each component was taken from the SIMAPRO 5.0 database and the weight of each component was used to evaluate its environmental impact by weight (see Table 4). We calculate the Eco-indicator score, by establishing an inventory of all emissions to air and water as well as the necessary resource extraction for product manufacture and then calculating the damages caused by these flows to three ecosystem impact categories, human health, ecosystem quality and resource use.

\section{Disposal options}

Currently three possible waste management options exist for the used NB waste stream. (1) Reuse via the second-hand market, (2) collection from TEPA sponsored centers with subsequent recycling for retrieval of valuable components and (3) disposal into the general waste stream with subsequent landfilling or incineration. Fig. 3 shows the flow for these three possible options that was used for the life cycle impact analysis described below.

The economic efficiency of the program was analyzed by using a model that integrates the results obtained from SIMAPRO with cost-benefit analysis (Pauli and Raimo, 1997). The model seeks a minimum value for environmental impact subject to the constraint of mass balance.

$$
\sum_{j=1}^{4} X_{j}=1
$$

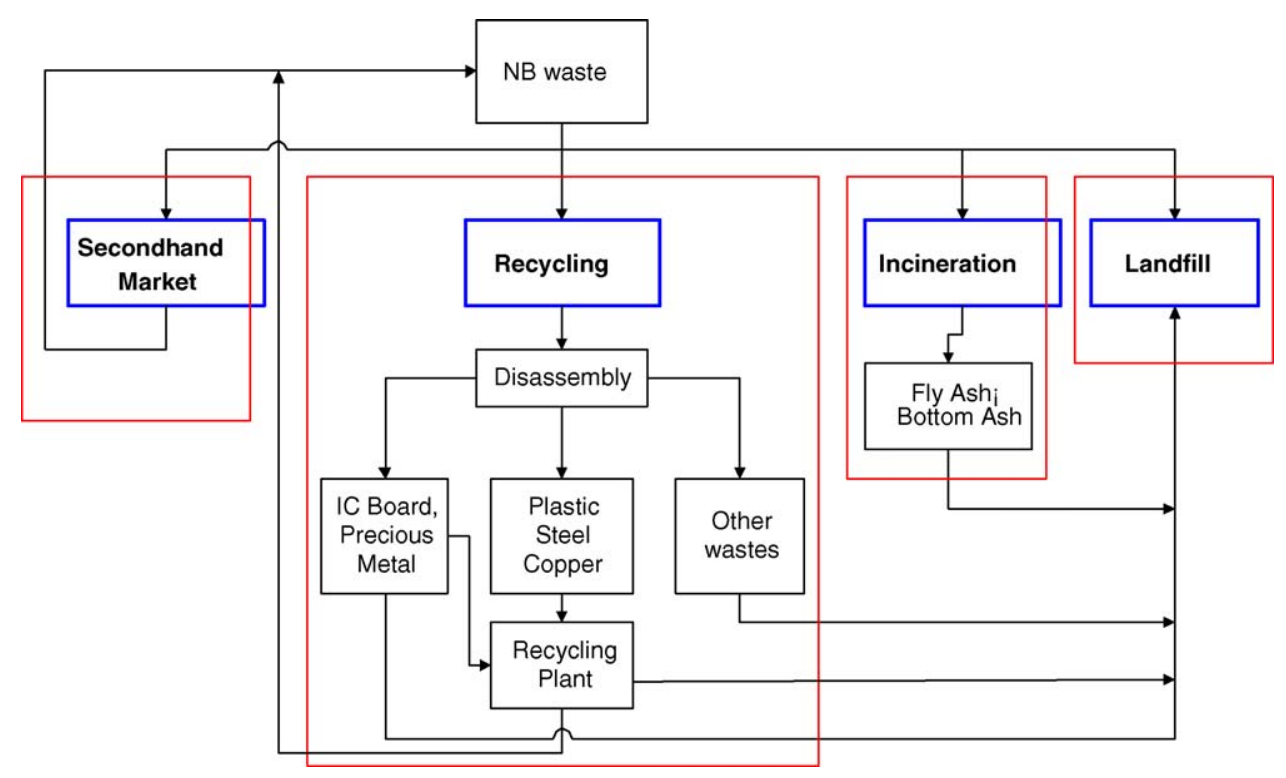

Fig. 3. NB disposal options in Taiwan. 

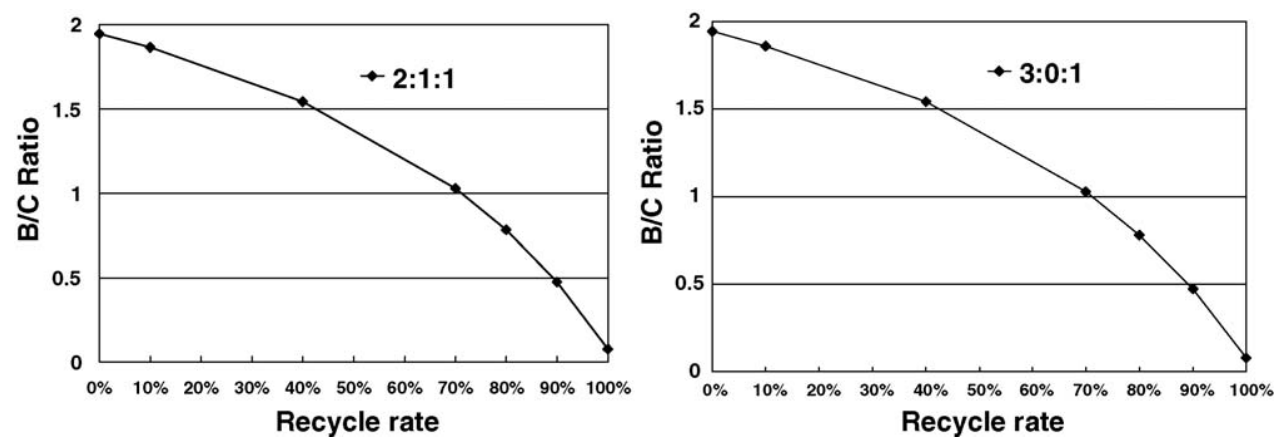

Fig. 4. The $B / C$ value for different recycle rates of obsolete NB's using ratios of 2:1:1 and 3:0:1 for incineration:landfill:second-hand market disposal options.

where $X_{j}$ is the fraction of obsolete NB's going to a particular disposal option. Acceptable solutions to the model must satisfy the constraint that the benefit/cost ratio is greater than 1, i.e., $B / C>1$, where $B$ is the benefit per unit obsolete NB's and $C$ is the cost per unit. For a discussion of the computation of benefits $(B)$ and costs $(C)$ see Appendix A.

Input to the model consists of scenarios using various combinations of disposal options (recycling plants, second-hand markets, landfill and incineration). A total of 13 scenarios were examined. Seven values for the recycling rate were selected, 0, 10, 40, 70, 80, 90 and $100 \%$, using two ratios for the remaining disposal options, 3:0:1 and 2:1:1, for incineration:landfills:second-hand markets. Fig. 4 shows the $B / C$ value for each scenario.

The environmental impact corresponding to each scenario was defined using SIMAPRO to generate an environmental impact value. Table 6 represents the LCA results for 13 disposal scenarios.

Table 6

LCA analysis results for model scenarios of NB's

\begin{tabular}{|c|c|c|c|c|c|c|c|c|c|c|c|c|c|}
\hline Scenario & 1 & 2 & 3 & 4 & 5 & 6 & 7 & 8 & 9 & 10 & 11 & 12 & 13 \\
\hline $\begin{array}{l}\text { Recovery } \\
\text { rate (\%) }\end{array}$ & 0 & 0 & 10 & 10 & 40 & 40 & 70 & 70 & 80 & 80 & 90 & 90 & 100 \\
\hline $\begin{array}{l}\text { Incineration } \\
\text { ratio }\end{array}$ & $3 / 4$ & $1 / 2$ & $3 / 4$ & $1 / 2$ & $3 / 4$ & $1 / 2$ & $3 / 4$ & $1 / 2$ & $3 / 4$ & $1 / 2$ & $3 / 4$ & $1 / 2$ & 0 \\
\hline Landfill ratio & 0 & $1 / 4$ & 0 & $1 / 4$ & 0 & $1 / 4$ & 0 & $1 / 4$ & 0 & $1 / 4$ & 0 & $1 / 4$ & 0 \\
\hline $\begin{array}{l}2^{\text {nd }} \text { hand } \\
\text { ratio }\end{array}$ & $1 / 4$ & $1 / 4$ & $1 / 4$ & $1 / 4$ & $1 / 4$ & $1 / 4$ & $1 / 4$ & $1 / 4$ & $1 / 4$ & $1 / 4$ & $1 / 4$ & $1 / 4$ & 0 \\
\hline $\begin{array}{l}\text { Human } \\
\text { Health Index } \\
\text { (\%) }\end{array}$ & 100.0 & 100.0 & 103.1 & 103.1 & 113.2 & 113.2 & 122.9 & 122.0 & 126.0 & 126.0 & 129.5 & 129.5 & 132.6 \\
\hline $\begin{array}{l}\text { Ecosystem } \\
\text { Quality } \\
\text { Index } \\
(\%)\end{array}$ & 100 & 100 & 103.2 & 103.2 & 113.2 & 113.2 & 123.1 & 122.3 & 126.3 & 126.3 & 129.5 & 129.5 & 132.8 \\
\hline $\begin{array}{l}\text { Resources } \\
\text { Consumption } \\
\text { Index (\%) }\end{array}$ & 100 & 100 & 103.2 & 103.2 & 112.9 & 112.9 & 122.6 & 121.6 & 126 & 126 & 129.1 & 129.1 & 132.3 \\
\hline
\end{tabular}


Scenarios $1-8$ satisfy the constraint that the ratio $B / C>1$. All these scenarios have NB recycling rates below $70 \%$. For the smallest environmental impact value the best solutions were scenario 1 and 2 . An assessment of $B / C$ shows that when $B / C$ is at 1 , the marginal recycling rate of obsolete NB's going to recycling plants is 70-80\%.

Table 6 shows that independent of the fraction going to landfill and incineration, the calculated human health index rises with the increasing recovery rate. Because we have seen that the control unit is the main contributor to environmental impact from the recycling process, our results suggest that increased reuse of the control unit, or alternatively, redesign of the control unit, offers the most effective strategy for improving life cycle environmental management of NBs and diminishing their negative contribution to environmental impact.

\section{The international dimension}

Our analytic results show that aside from product or component reuse the prime focus for reducing the environmental impacts of NBs over the commercial life cycle should be during the design phase of the product life cycle. Over the past two decades Taiwan has emerged as a central hub in the global manufacture of NBs as well as other consumer electronics including semi-conductors, PC boards and desktop computers. Table 7 shows the growth of NB production from 1995 to 2003 for Taiwan compared to the rest of the world. The table makes plain the accelerated growth evident for Taiwan in this international development, with Taiwan capturing nearly two-thirds of the global market share by 2003. The prominent position occupied by Taiwan in the global supply and production chain requires that Taiwan's domestic policies consider other national policies for electronics waste disposal as well as the establishment of global environmental management standards.

The global production numbers represent the units assembled in Taiwan and include components manufactured domestically as well as others that are supplied by foreign sources, increasingly mainland China. Despite the fact that many components, including the control unit, are manufactured elsewhere, Taiwan's central role in global manufacturing, offer it a unique opportunity to play a role in improving the environmental character of this product by influencing suppliers in Shanghai and consumers in Paris. The international perspective and the domestic experience both advocate for more direct involvement by manufacturers in

Table 7

NB Production, growth rates and market share for Taiwan

\begin{tabular}{|c|c|c|c|c|c|c|c|c|c|}
\hline & 1995 & 1996 & 1997 & 1998 & 1999 & 2000 & 2001 & 2002 & 2003 \\
\hline $\begin{array}{l}\text { Global Shipments } \\
\text { (1000 units) }\end{array}$ & 8919 & 11807 & 14453 & 16852 & 19230 & 22260 & 25180 & 29470 & 37540 \\
\hline $\begin{array}{l}\text { Shipments from } \\
\text { Taiwan (1000 units) }\end{array}$ & 2592 & 3781 & 4465 & 6070 & 9350 & 11620 & 14760 & 18199 & 24253 \\
\hline Global growth rate $(\%)$ & 21.2 & 32.4 & 22.4 & 16.6 & 14.1 & 15.8 & 13.1 & 17.0 & 27.3 \\
\hline $\begin{array}{l}\text { Growth rate in Taiwan } \\
(\%)\end{array}$ & 26.0 & 45.9 & 18.1 & 26.6 & 54.0 & 24.3 & 27.0 & 23.2 & 33.2 \\
\hline $\begin{array}{l}\text { Taiwan's global market } \\
\text { share }(\%)\end{array}$ & 29.1 & 32.0 & 30.9 & 36.4 & 48.6 & 52.2 & 58.6 & 61.7 & 64.6 \\
\hline
\end{tabular}

Source: Institute for Information Industry, MIC, Taiwan (2003). 
domestic recycling activity that promises to provide feedback between design for environment initiatives for NB design and the development of recycling or recovery technologies.

\section{Findings and conclusions}

Though the preceding analysis was conducted for Taiwan, our conclusions should generally apply to national policies. This case study of Taiwan's current system for management of used NBs and components reveals that:

- Increasing the rate of obsolete NB's going to recycling plants implies an increase in the environmental impact value, and a decrease in the $B / C$ value.

- The higher the recycling rate the more serious the environmental impact.

- The second-hand market for used goods influences participation in recycling programs.

- Examining the environmental impact of various end of life waste management options may affect the desirability of particular management strategies such as recycling.

- Government waste management programs should ensure that sufficient capital is available for research and development of recovery technologies.

- Environmental initiatives in other countries affect local waste management policies.

Therefore, we recommend that:

- A revised domestic policy in Taiwan place greater emphasis on the reuse of second-hand NBs rather than a narrow focus on recycling.

- A revised domestic policy in Taiwan strengthen the economic incentive provided to recycling agents.

- A revised domestic policy in Taiwan involve manufacturers directly in the actual recycling process and the development of new recycling technology.

- A revised domestic policy in Taiwan mandate efforts during the design stage of electronic products.

- A revised domestic policy in Taiwan provide a new model for international coordination in trade and waste management by considering international waste management initiatives, such as those in the EU and Japan, to reduce the environmental impacts from electronic products over the product life cycle. For the case of NBs, the redesign of LCDs and control unit $\mathrm{s}$ for easier value recovery through disassembly and reduced hazardous materials content is urgently needed.

\section{Appendix A. Benefit-cost calculation details}

In our model the ratio of the benefit to cost per unit obsolete NB's must be greater than or equal to 1 , i.e., $B / C>1$, where $B$ is the benefit and $C$ is the cost per unit obsolete NB.

$B$ is the sum of the benefit gained from recycling and the selling price of a NB's in the second-hand market for a given scenario.

$$
B=\sum_{j=1}^{2}(\mathrm{BF})_{j} \times X_{j}
$$


where BF represents the recycling benefit or the selling price of a NB's in the second-hand market at $j$ condition. For $j=1,(\mathrm{BF})_{j}$ is the selling price for a second-hand NB's and $X_{j}$ is the fraction of obsolete NB's going to the second-hand market. For $j=2,(\mathrm{BF})_{j}$ is the final selling price for recycling materials from NB's and $X_{j}$ is the fraction of obsolete NB's going to recycling facilities.

$C$ is the sum of transportation cost and treatment cost.

$$
C=\mathrm{TS} \times X_{j}+\sum_{j=1}^{4} \mathrm{TT}_{j} \times X_{j}
$$

where TS is the average transportation cost for NB's going to recycling plants, incineration, landfills and second-hand markets (assuming that the transporting distances are the same and the disposal fee per unit is equal) and $\mathrm{TT}_{j}$ is the average environmental impact value of environmental impact indicator $i$ for disposal option $j$.

\section{Appendix B. Inventory of major emissions to air and water and resource extraction for the life cycle of a typical NB}

\begin{tabular}{|c|c|c|c|c|c|}
\hline \multicolumn{2}{|l|}{ Air (mg) } & \multicolumn{2}{|l|}{ Raw (g) } & \multicolumn{2}{|l|}{ Water (mg) } \\
\hline Substance & Total & Substance & Total & Substance & Total \\
\hline $\mathrm{SO}_{2}$ & $1.24 \mathrm{E}+09$ & Water & $7.10 \mathrm{E}+05$ & COD & $1.53 \mathrm{E}+05$ \\
\hline $\mathrm{CO}_{2}$ & $5.13 \mathrm{E}+07$ & Crude oil IDEMAT & $7.73 \mathrm{E}+03$ & $\mathrm{Cl}^{-}$ & $1.39 \mathrm{E}+05$ \\
\hline $\mathrm{NO}_{x}$ & $2.12 \mathrm{E}+05$ & Natural gas & $3.78 \mathrm{E}+03$ & Sulphates & $7.45 \mathrm{E}+04$ \\
\hline Methane & $1.23 \mathrm{E}+05$ & Copper (in ore) & $8.67 \mathrm{E}+02$ & Unspecified emission & $5.52 \mathrm{E}+04$ \\
\hline $\mathrm{C}_{x} \mathrm{H}_{y}$ & $6.32 \mathrm{E}+04$ & Lignite & $4.01 \mathrm{E}+02$ & $\mathrm{Na}$ & $4.57 \mathrm{E}+04$ \\
\hline $\mathrm{SO}_{x}$ & $4.95 \mathrm{E}+04$ & Marl & $2.40 \mathrm{E}+02$ & $\mathrm{Cu}$ & $2.40 \mathrm{E}+04$ \\
\hline $\mathrm{CO}$ & $2.64 \mathrm{E}+04$ & Cobalt (in ore) & $2.18 \mathrm{E}+02$ & $\mathrm{Al}$ & $1.54 \mathrm{E}+04$ \\
\hline VOC & $1.84 \mathrm{E}+04$ & Rock salt & $1.37 \mathrm{E}+02$ & Kjeldahl-N & $1.53 \mathrm{E}+04$ \\
\hline Non-methane VOC & $8.07 \mathrm{E}+03$ & Chromium (in ore) & $1.10 \mathrm{E}+02$ & Calcium compounds & $1.43 \mathrm{E}+04$ \\
\hline $\mathrm{NO}_{2}$ & $1.39 \mathrm{E}+03$ & Wood & $1.02 \mathrm{E}+02$ & $\mathrm{Mg}$ & $1.30 \mathrm{E}+04$ \\
\hline Silicates & 756.58 & Sand & 94.94 & Suspended substances & 8393.70 \\
\hline $\mathrm{Al}$ & 494.30 & Iron (in ore) & 91.30 & Dissolved substances & 6913.46 \\
\hline $\mathrm{C}_{x} \mathrm{H}_{y}$ aromatic & 422.16 & Molybdene (in ore) & 86.13 & Calcium ions & 6024.94 \\
\hline Propane & 361.40 & Silver & 81.32 & Sulphate & 5711.05 \\
\hline Pentane & 320.75 & Methane (kg) & 67.79 & TOC & 5428.66 \\
\hline Soot & 279.18 & Manganese (in ore) & 65.91 & $\mathrm{Fe}$ & 4903.58 \\
\hline NO & 267.90 & Uranium (in ore) & 65.43 & $\mathrm{~K}$ & 4796.24 \\
\hline Butane & 267.02 & Tin (in ore) & 45.10 & $\mathrm{~Pb}$ & 4335.10 \\
\hline $\mathrm{N}_{2} \mathrm{O}$ & 239.97 & Zeolite & 41.56 & Phosphate & 4035.00 \\
\hline Formaldehyde & 238.05 & Gas from oil production & 35.99 & $\mathrm{Sn}$ & 2960.21 \\
\hline $\mathrm{H}_{2}$ & 221.66 & Limestone & 29.47 & Baryte & 2329.18 \\
\hline $\mathrm{Fe}$ & 206.94 & Platinum (in ore) & 18.35 & BOD & 1721.06 \\
\hline Acetone & 185.76 & Lead (in ore) & 17.15 & Nitrate & 1388.84 \\
\hline HALON-1301 & 184.33 & Barite & 11.34 & $\mathrm{C}_{x} \mathrm{H}_{y}$ & 1388.78 \\
\hline $\mathrm{HCl}$ & 160.78 & Coal & 10.58 & $\mathrm{Ba}$ & 1329.07 \\
\hline $\mathrm{Mg}$ & 159.16 & Palladium (in ore) & 9.40 & Dissolved organics & 1287.90 \\
\hline Xylene & 135.19 & Rhodium (in ore) & 8.01 & $\mathrm{Ti}$ & 1195.54 \\
\hline
\end{tabular}


Appendix B (Continued)

\begin{tabular}{|c|c|c|c|c|c|}
\hline \multicolumn{2}{|l|}{ Air (mg) } & \multicolumn{2}{|l|}{ Raw (g) } & \multicolumn{2}{|l|}{ Water (mg) } \\
\hline Substance & Total & Substance & Total & Substance & Total \\
\hline $\mathrm{H}_{2} \mathrm{~S}$ & 121.12 & Bauxite & 5.38 & $\mathrm{NH}_{4}^{+}$ & 1190.39 \\
\hline Ammonia & 118.77 & Bentonite & 3.18 & & \\
\hline Benzene & 105.69 & & & & \\
\hline Aldehydes & 102.89 & & & & \\
\hline Toluene & 82.45 & & & & \\
\hline $\mathrm{Ca}$ & 76.77 & & & & \\
\hline Dichloromethane & 74.16 & & & & \\
\hline $\mathrm{C}_{x} \mathrm{H}_{y}$ chloro & 62.97 & & & & \\
\hline
\end{tabular}

Total energy $=51.641648 \mathrm{MJ}$.

\section{References}

Atlantic Consulting and IPU. LCA study of product group personal computers in the EU Ecolabel scheme. Institute for Product Development of the Technical University of Denmark; 1998. p. 6-33.

Chang SL. The determination of recycling fees for computers and accessories. Taipei,Taiwan: Final Report to Environmental Protection Administration; 1998.

Chiang KY. The standard, number and recycling of seven waste information products including motherboard, HD, CRT/LCD monitor, case, power supply, notebook PC and printer; 2000 (December). p. 4-8.

Institute for Information Industry (III). Annual Report. Taiwan: Market Intelligence Center (MIC); 2003 [in Chinese].

Japan Ministry of Economy, Trade and Industry, Home Appliance Recycling Law. Entry into force: April 2001. Promulgated June 1998; For text in English see http://www.meti.go.jp/policy/kaden_recycle/en_cha/ pdf/english.pdf.

Lee CH, Chang SL, Wang KM, Wen LC. Management of scrap computer recycling in Taiwan. J Hazard Mater 2000;A73:209-20.

Matthews HS, Hendrickson C, McMichael FC, Hart DJ. Disposition and end-of-life options for products: a green design study. Carnegie Mellon University: Green Design Initiative Technical Report \#97-10. Last updated August 1999.

Pauli M, Raimo PH. How to benefit decision analysis in environmental life CYCLE assessment. Eur J Operat Res 1997;102:279-94.

Product Ecology Consultants. User guide for SIMARO; 2001.

TEPA (Taiwan Environmental Protection Administration). Environmental protection statistics of Taiwan 2001 [in Chinese].

The European Parliament and the council of the European Union. Directive 2002/96/Ec of the European Parliament and of the council of 27 January 2003 on Waste Electrical and Electronic Equipment (WEEE). Official J Euro Union, L 37/24; 2003. http://www.Aeanet.Org/Governmentaffairs/Ewwroemwcvczvxrhmnnuchgysskbdx.pdf [13.2.2003].

Tung RA, Wu SC. Assessment and research on the recycling technology of waste notebook computers-assessing the feasibility of LCD recycling technology. EPA-88-HA-21-03-0006; 1999. p. 1-1-2-26 [in Chinese].

USGS (United States Geological Survey). Obsolete Computers, Gold Mine, or High-Tech Trash? Resource Recovery from Recycling, Science for a changing world. U.S. Department of the Interior; 2001. http://pubs.usgs.gov/fs/fs060-01/. 